Bundesgesundheitsbl 2018 $\cdot 61: 116-128$ https://doi.org/s://dx.doi.org/ 10.1007/s00103-017-2661-3

๑) Springer-Verlag GmbH Deutschland 2017

Mitteilungen des Arbeitskreises Blut des Bundesministeriums für Gesundheit

\title{
Humanes Cytomegalievirus (HCMV)
}

\section{Stellungnahmen des Arbeitskreises Blut des Bundesministeriums für Gesundheit}

rushülle befindet sich eine als Tegument bezeichnete Proteinschicht. Die Virushülle leitet sich von zellulären Membranen ab. In die Lipiddoppelmembran sind mindestens acht verschiedene virale Glykoproteine eingelagert. Das reife Viruspartikel hat einen Durchmesser von 150-200 nm (• Abb. 1). Wie alle Herpesviren ist HCMV empfindlich gegen niedrigen $\mathrm{pH}$, Lipidlösungsmittel und Hitze. Bei $37^{\circ} \mathrm{C}$ nimmt die HCMV-Infektiosität nach 60 Minuten um ungefähr die Hälfte ab. Das Virus ist auch bei $-20^{\circ} \mathrm{C}$ instabil. Falls für wissenschaftliche Zwecke vitale Viren aufbewahrt werden sollen, müssen Proben bei mindestens $-70^{\circ} \mathrm{C}$ gelagert werden.

Nach einer Infektion mit Herpesviren beobachtet man den lytischen Infektionszyklus und die Latenz. Die Latenz besteht lebenslang. Charakteristika der Betaherpesviren, wie z. B. bei HHV-5, HHV-6 und
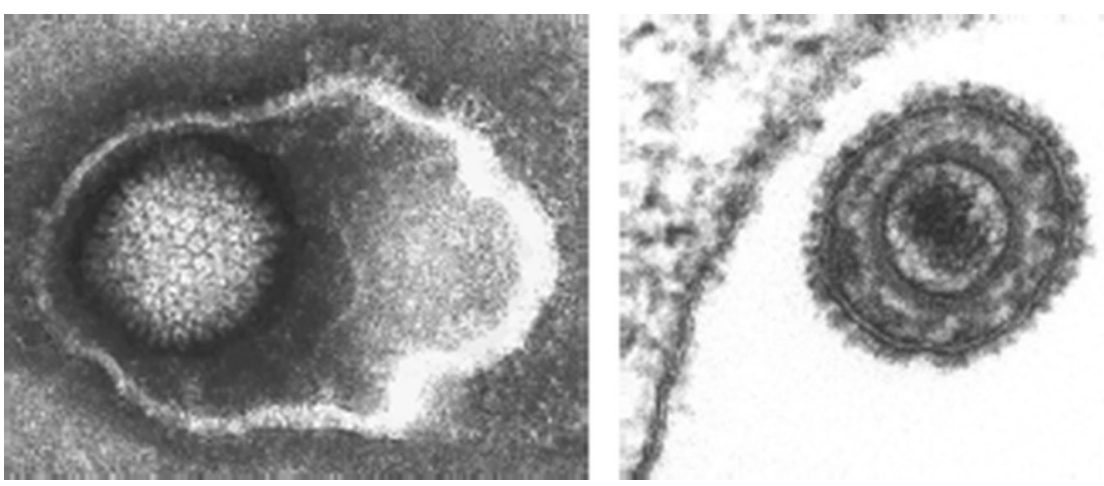

Abb. 1 ॥ Elektronenmikroskopische Aufnahmen von HCMV-Partikeln Linkes Bild: Negativkontrastierung: auf der dilatierten Virushülle sind teilweise die Oberflächenproteine (Glykoprotein) sichtbar. Das Kontrastmittel ist in das Viruspartikel eingedrungen (Deformierung der Lipidhülle), und im Innern ist das Nukleokapsid mit seinen Untereinheiten zu erkennen.

Rechtes Bild: Ultradünnschnitt durch ein Viruspartikel. Im Innern des Virion ist die Nukleinsäure (DNA) stark mit dem Kontrastmittel angefärbt. Zwischen Kapsid und Virushülle erkennt man die Proteinschicht des Teguments. Auf der Lipiddoppelmembran ist der dichte Saum der Glykoproteine zu erkennen. Foto mit freundlicher Genehmigung (๑ HR Gelderblom, Robert Koch-Institut) 
Wirtszelle, wobei Tegumentproteine des infizierenden Viruspartikels als Transaktivatoren der IE-Gene wirken.

Die IE-Proteine regulieren die weiteren Schritte der Virusvermehrung und greifen in die Regulation der Zelle ein, unter anderem in die Expression und den Transport der HLA-Antigene (MHC Klasse-1-Proteine) zum Proteasom. IEProteine (vor allem das Phosphoprotein pp65) können als frühe Marker der Virusinfektion verwendet werden. $\mathrm{Zu}$ den frühen E-Proteinen gehört die HCMV-kodierte DNA-Polymerase, deren Aktivität durch das Zusammenwirken von viralen Nukleotidkinasen und antiviralen Substanzen spezifisch gehemmt werden kann.

Die Synthese der Strukturproteine (LProteine) wird über die E-Proteine reguliert. Das Zusammensetzen der viralen Kapside erfolgt im Zellkern; Ausschleusung und Umhüllung der Viren erfolgen an der inneren Kernmembran (möglicherweise auch an anderen zellulären Membranen). HCMV zeigt eine ausgeprägte Zellassoziation [1].

Untersuchungen mit monoklonalen Antikörpern weisen auf Unterschiede von Virusstämmen und -isolaten hin. Unter Verwendung von primären Isolaten und den korrespondierenden Seren der Patienten konnte gezeigt werden, dass isolatspezifische neutralisierende Antikörper gebildet werden. Ob wie bei anderen $\mathrm{Vi}$ rusfamilien die Variabilität von Antigenen oder das Vorhandensein von unterschiedlichen Subtypen von HCMV für die Bildung von isolatspezifischen Antikörpern verantwortlich sind, ist unklar [2].

\subsection{Infektion und Infektionskrankheiten}

Bei Immunkompetenten verlaufen die meisten HCMV-Infektionen asymptomatisch oder mit leichten, wenig charakteristischen Symptomen und zum Teil unter dem Bild einer Mononukleose. HCMV gelangt über Schleimhautkontakte oder parenteral (über zellhaltige Blutkomponenten, durch Stammzell-/Organtransplantation) in den Organismus. Das Virus kann außerdem transplazentar sowie über zervikale, vaginale Sekrete und Muttermilch auf den Föten bzw. das Kind (peri- und postnatale Infektion) übertragen werden. Bei Immuninkompetenten kann es zu einer generalisierten Infektion mit Organbeteiligung wie Enzephalitis, Pneumonie, Retinitis, Hepatitis, Nephritis, Splenomegalie und Colitis kommen. Es sind auch schwere Verläufe bei anderen parallel bestehenden Infektionen sowie Transplantatdysfunktionen und -verluste beschrieben worden. Insgesamt führt eine HCMV-Infektion neben den unmittelbaren klinischen Symptomen zu einer unspezifischen Inhibition der zellulären und humoralen Abwehr u. a. durch die Inhibition von CD4-positiven T-Lymphozyten [3-8].

Die Inkubationszeit beträgt 4-6 Wochen. In dieser Zeitspanne kommt es zu einer im Vergleich mit der Phase der frühen Serokonversion geringeren Virämie mit Konzentrationen unter 100 IU/ $\mathrm{ml}$. Als Ursache für den verzögerten Virusanstieg wird nach einer Tröpfcheninfektion eine primär lokal in der nasopharyngealen Schleimhaut ablaufende lytische Phase mit Induktion der Bildung erster, nicht neutralisierender Antikörper diskutiert. Erst nach einigen Tagen bis Wochen erfolgt dann die virämische HCMV-Ausbreitung, die u. a. durch die Bildung neutralisierender Antikörper z. B. gegen HCMV-Glykoprotein B terminiert wird [9].

Nach der Infektion kann HCMV über einen längeren Zeitraum passager über Urin und Speichel ausgeschieden werden. Die Reaktivierung von latenten Infektionen kann zur sporadischen Virusausscheidung führen. Die neonatal erworbene HCMV-Infektion führt zur stärkeren und längeren chronischen Virusausscheidung als eine später erworbene Infektion.

Die Virusreplikation kann in vielen Zellen und Geweben (z.B. epithelialen Zellen, Endothelzellen, verschiedenen Parenchymzellen, mononukleären Zellen des Blutes) erfolgen. HCMV repliziert u.a. in Zellen innerer Organe und im Gehirn sowie wahrscheinlich auch in myeloiden Zellen bei der Reifung zu differenzierten Makrophagen und dendritischen Zellen [10]. Weiterhin werden duktale Epithelien der Speicheldrüsen von HCMV befallen, daneben auch Nierenepithelien und Drüsenzellen der Genitalorgane [11]. Während der Virämiephase kann HCMV über Körperflüssigkeiten wie Speichel,
Urin, Ejakulat und vaginale Sekrete ausgeschieden werden. Jede Person mit einer HCMV-Infektion - auch ohne klinische Symptomatik - kann das Virus übertragen.

Vergleichbar mit anderen Herpesviren geht die primäre Infektion mit HCMV unabhängig vom klinischen Verlauf (s. unten) in den Zustand der Latenz über, die lebenslang bestehen bleibt. Als zelluläre Latenzorte (Reservoire) im Blut und Knochenmark werden diskutiert [12-17]:

- CD34-positive hämatopoetische Progenitorzellen,

- CD33-positive myeloische Progenitorzellen,

- Monozyten

- Dendritische Zellen

- Neutrophile Granulozyten

- Makrophagen.

Roback et al. gewannen 6-8 Wochen nach CMV-Infektion von Mäusen Leukozyten, die sie in eine granulozytenreiche bzw. monozytenreiche Fraktion aufteilten. Beide Fraktionen wurden CMV-naiven Mäusen transfundiert. Nur die Monozyten übertrugen, in Abhängigkeit von der applizierten Zellmenge, bei 35-50\% der Mäuse CMV [16]. Inwieweit die Ergebnisse auf den Menschen übertragen werden können, bleibt offen.

Prinzipiell muss man zwischen einer HCMV-Infektion und einer HCMVErkrankung differenzieren. Bei einer HCMV-Erkrankung werden Schädigungen von Geweben und Organen sowohl durch direkte zytotoxische Wirkungen von HCMV, durch Induktion zytotoxischer T-Lymphozyten und $\gamma$-InterferonProduktion, durch spezifische CD4-positive T-Lymphozyten und durch natürliche Killerzellen als auch durch indirekte, HCMV-induzierte immunpathologische Mechanismen (z.B. Immunsuppression, Bildung proinflammatorischer Zytokine) verursacht $[7,10]$.

\section{Kongentitale HCMV-Infektion}

Die Inzidenz der kongenitalen HCMVInfektion liegt zwischen $0,3 \%$ und $1,2 \%$. [1]. Damit stellt die HCMV-Übertragung die häufigste kongenitale Infektion dar. Kongenitale Infektionen resultieren zumeist aus einer primären Infektion der Mutter während der Schwangerschaft 
mit einer intrauterinen Transmissionsrate von $40-50 \%$. Weiterhin kann HCMV bei präkonzeptionell HCMV-seropositiven Schwangeren reaktiviert werden, oder die Schwangeren können mit einem weiteren HCMV-Stamm superinfiziert werden (maternale Sekundärinfektion) mit der Folge einer Infektionsrate von $1 \%$ der Neugeborenen [1]. Etwa 7-10\% der infizierten Kinder entwickeln Symptome einer HCMV-Erkrankung mit z.B. Petechien, Ikterus, Hepatosplenomegalie, Chorioretinitis und z.T. bleibenden neurologischen Störungen (z.B. geistige Retardierung, Schwerhörigkeit bis zur Taubheit, motorische Defizite), an deren Folgen etwa $10 \%$ der Erkrankten versterben $[4,7]$. Ein weiterer Infektionsweg ist die Muttermilch-assoziierte postnatale HCMV-Transmission, die bei bis zu 35$40 \%$ der Frühgeborenen seropositiver Mütter auftreten kann, die bezüglich einer HCMV-Erkrankung wesentlich stärker als Reifgeborene gefährdet sind [1, 1820]. Durch Einfrieren der Muttermilch bei ca. - 20 C für mindestens 24 Stunden kann durch die kältebedingte Minderung der Infektiosität eine Verringerung der Transmissionsrate erreicht werden [20-23]. Die Infektion mit HCMV verläuft bei Reifgeborenen meist symptomlos.

\section{HCMV-Infektionen bei Gewebe- und Organtransplantation}

Wichtige pathogenetische Mechanismen für das Auftreten einer HCMV-Erkrankung bei Empfängern von Gewebe- oder Organtransplantaten sind einerseits eine Neuinfektion bei fehlender Immunität und/oder Immunsuppression und andererseits die Reaktivierung des latenten Virus bei vorbestehender HCMV-Infektion des Empfängers [7]. Die Reaktivierung von HCMV kann ausgelöst oder verstärkt werden u. a. durch Interaktionen mit anderen Viren (z. B. HHV-6) oder eine gesteigerte Produktion von Zytokinen bis hin zum "cytokine storm“ während bakterieller Infektionen, einer Graft-versus-host disease (GVHD) oder immunsuppressiver Behandlung z. B. mit antilymphozytären Antikörpern.

Das Risiko für das Auftreten einer HCMV-Erkrankung kann aus folgenden Informationen abgeschätzt werden $[7,10]$ :
- Serostatus von Spender und Empfänger,

- Art und Intensität der immunsuppressiven Behandlung,

- interkurrente schwer verlaufende Infektionen,

- Auftreten einer Hepatitis nach Lebertransplantation oder GVHD nach allogener Stammzelltransplantation.

Auch die Art des transplantierten Organs beeinflusst die Entwicklung einer HCMVErkrankung. Das Risiko ist am höchsten nach Lungen-, geringer nach Herz-/Leber- und am geringsten nach Nierentransplantation. Während bei Empfängern von allogenen Stammzelltransplantaten eine HCMV-Pneumonie und seltener gastrointestinale Ulzera sowie Retinitis die wichtigsten Manifestationen der HCMV-Erkrankung sind [24, 25], führt die HCMV-Erkrankung nach Transplantation solider Organe von HCMV-seropositiven Spendern zumeist zu einer Schädigung des transplantierten Organs (z. B. Hepatitis nach Lebertransplantation und Pneumonie nach Lungentransplantation) $[7,26]$.

Infolge immunmodulatorischer Effekte seiner Glykoproteine besitzt HCMV bei transplantierten Patienten darüber hinaus pathogenetische Bedeutung für akute oder chronische Abstoßungsreaktionen. Zudem begünstigt die durch HCMV ausgelöste Immunsuppression das Auftreten bakterieller und fungaler Superinfektionen bzw. opportunistischer Infektionen sowie Epstein-Barr-assoziierter lymphoproliferativer Erkrankungen (posttransplantation lymphoproliferative disorders, PT-LPD) [10].

\section{HCMV-HIV-Koinfektionen}

HIV-infizierte Personen sind sehr häufig HCMV seropositiv und erkranken bei fortschreitender Immunsuppression in Folge einer Reaktivierung des latenten Virus und nur selten durch eine primäre Infektion. Das Auftreten einer HCMV-Erkrankung korreliert mit dem Schweregrad der Immunschwäche, wobei insbesondere Patienten mit einem Abfall der CD4-positiven T-Lymphozyten auf $<50-100 / \mu$ betroffen sind. Im Vordergrund der durch HCMV ausgelösten direkten zytotoxischen Wirkungen bei
AIDS-Patienten steht die meistens einseitig beginnende, später auch beidseitig auftretende HCMV-Retinitis, die zur Erblindung führen kann. Nach Einführung der hochaktiven antiretroviralen Therapie (HAART) ist die HCMV-Retinitis selten geworden. Gleichzeitig wurde jedoch unter HAART ein Auftreten intraokulärer Entzündungen beobachtet, die als Antwort des Immunsystems auf persistierende virale Proteine in HCMV-Läsionen der Retina interpretiert werden [27]. Weitere Krankheitsmanifestationen (z. B. Gastroenteritis, Colitis, Pneumonie, Meningoenzephalitis, Iritis, Polyradikulopathie) können auftreten.

Bei Patienten, die wegen einer malignen Grunderkrankung eine (Poly-)Chemotherapie und/oder Bestrahlung erhalten, kommt es oft zu einer passageren Störung der zellulären Immunität, die jedoch nur selten zu einer HCMV-Erkrankung als Folge einer primären oder sekundären Infektion führt [28].

\subsection{Epidemiologie}

Die Prävalenz spezifischer Antikörper gegen das ubiquitär vorkommende HCMV weist eine große Variationsbreite in Abhängigkeit vom sozioökonomischen Standard eines Landes auf [29]. Generell ist die Prävalenz in den Industriestaaten Amerikas, Westeuropas und in Australien niedriger als in Entwicklungsländern. Für viele Länder in Afrika und Asien sowie Japan wird die Prävalenz HCMV-spezifischer Antikörper im Erwachsenenalter mit bis zu $100 \%$ angegeben, während sie in den westlichen Industriestaaten zwischen 40 und $70 \%$ liegt [30, 31].

Die Wahrscheinlichkeit einer durchgemachten HCMV-Infektion nimmt mit dem Lebensalter zu und erreicht bis zum 6. Lebensjahr zwischen 5 und $30 \%$. Die Durchseuchung der Bevölkerung in Industriestaaten erfolgt zweiphasig: Ein erster Gipfel, verursacht vorwiegend durch Kontaktinfektionen, wird in den ersten zwei bis drei Lebensjahren beobachtet. Ein zweiter Gipfel tritt in der Jugend und im jungen Erwachsenenalter etwa zwischen 16 und 30 Jahren auf und wird insbesondere durch Küssen und Sexualkontakte verursacht [32]. Der Anteil der Seropositiven steigt danach mit zunehmendem Lebensalter auf $50 \%$ bis $70 \%$ an [33]. 


\subsection{Nachweismethoden}

Zur Diagnostik einer HCMV-Infektion stehen der direkte Virusnachweis durch Zellkultur, der Nachweis von viralen Antigenen, von HCMV-DNA, von HCMVspezifischen IgM- und IgG-Antikörpern bzw. der Nachweis von T-Zell-Antworten gegen HCMV zur Verfügung, die je nach Fragestellung eingesetzt werden können [zusammenfassend: 34]. Die primäre Diagnostik einer HCMV-Infektion kann durch Nukleinsäure-Amplifikationstechniken (NAT) oder den Antigennachweis (pp65) z. B. in Leukozyten in Blut, Plasma, Speichel und Urin sowie vor der Serokonversion mittels Virusisolierung erfolgen [32, 33, 35]. Die Serokonversion wird durch den Nachweis von HCMVspezifischen IgM- und/oder IgG-Antikörpern im Serum festgestellt. Dafür stehen sowohl ELISA, Immunoblots als auch Immunfluoreszenzteste zur Verfügung.

Serologisch kann über den IgM- und den IgG- Nachweis eine Infektion mit HCMV erkannt werden. Mit serologischen Testen kann auch der Serostatus festgestellt werden [36]. Die Reaktivierung (oder Sekundärinfektion) kann serologisch durch Nachweis eines signifikanten Titeranstiegs HCMV-spezifischer Antikörper festgestellt werden. Weiterhin kann durch die Aviditätsbestimmung der IgG-Antikörper zwischen einer primären Infektion (niedrige Avidität bei Bindung gegen multivalentes Antigen) und einer sekundären Infektion (hohe Avidität) insbesondere bei Diagnostik der HCMV-Infektion in der Schwangerschaft unterschieden werden. Der Immunoblot wird als Standard zur serologischen Bestätigung auch von IgM-Antikörpern im Serum betrachtet [37, 38].

Bei Transplantationspatienten wird zum Monitoring vor allem der quantitative HCMV-DNA-Nachweis (NAT) aus Vollblut oder Plasma durchgeführt. Der quantitative Nachweis von pp65Antigen in Leukozyten ist wegen mangelnder Standardisierbarkeit, geringerer Sensitivität gegenüber NAT und der Notwendigkeit einer sehr kurzen Zeitspanne zwischen Blutentnahme und Untersuchung in den Hintergrund getreten. Für Säuglinge und IgG-defiziente Patien- ten mit dem Risiko eines „falsch“ positiven HCMV-IgG-Antikörpernachweises auf Grund eines passiven Antikörpertransfers von der Mutter oder durch Blutprodukte wurde kürzlich ein CD4T-Zellassay beschrieben. Nach HCMVspezifischer Stimulation ist der Nachweis von HCMV-spezifischen CD4-positiven T-Zellen über die Produktion von Zytokinen möglich [39]. Bei einer HCMV-Enzephalitis kann HCMV-DNA im Liquor nachweisbar sein. Eine genotypische Resistenzbestimmung mittels Sequenzierung kann bei ungenügendem therapeutischen Effekt antiviraler Substanzen sinnvoll sein $[35,40]$.

\section{Blut- und Plasmaspender}

\subsection{Prävalenz und Inzidenz bei Spenderkollektiven}

Repräsentative Untersuchungen zur Seroprävalenz in der Allgemeinbevölkerung in Deutschland liegen bisher nicht vor. Die Antikörperprävalenz bei Blutspendern liegt in Deutschland und anderen europäischen Ländern altersabhängig zwischen $37 \%$ und $65 \%$. Bei Blutspendern in Düsseldorf nahm die HCMVPrävalenz von ca. $33 \%$ bei den 18 bis 23-Jährigen bis auf etwa $73 \%$ bei den 61 bis 65-Jährigen zu [41]. Die Untersuchung von 24.260 Blutspendern in Gießen im Zeitraum von 1992-2002 ergab eine Seroprävalenz von $46 \%$. In dieser Langzeitstudie konnte die Serokonversionsrate bei diesen Blutspendern zwischen 18 und 60 Jahren mit $0,55 \%$ pro Jahr berechnet werden [42].

In Entwicklungsländern kann die Prävalenz bis zu $100 \%$ erreichen [42-44]. Die jährliche Inzidenz wird in unseren Breiten auf $0,6 \%$ bis $1,2 \%$ geschätzt [45-47]. Neuere, auf NAT-Ergebnissen basierende Daten, weisen auf eine Inzidenz von kleiner 0,8\%/Jahr für Deutschland hin $[9,48]$.

\subsection{Definition von Ausschlusskriterien}

Derzeit sind keine HCMV-spezifischen Ausschlusskriterien festgelegt. Bei klinischer Symptomatik wie z.B. Fieber, Lymphknotenschwellung u. ä. erfolgt eine Rückstellung von der Blutspende.

\subsection{Spendertestung und Aussagekraft}

Vor der Ära der Leukozytendepletion von Erythrozyten- und Thrombozytenkonzentraten wurden für Risikopatienten Spenden HCMV-seronegativer Spender ausgewählt. Präparate von HCMV-Antikörper-positiven Spendern wurden für diese spezielle Patientengruppe nicht eingesetzt. Jedoch kann der Einsatz von Erythrozyten- bzw. Thrombozytenkonzentraten von HCMV-seronegativen Spendern möglicherweise das relative Risiko der transfusionsassoziierten HCMVÜbertragung vergrößern. Es kann angenommen werden, dass sich ein gewisser Anteil unter den HCMV-serologisch negativen Spendern nach einer Erstinfektion in der virämischen Phase befindet. Die Wahrscheinlichkeit, eine unerkannt virämische Spende zur Transfusion zu verwenden, wäre daher größer, wenn die Spende nur aus der Spendersubpopulation "HCMV-seronegativ" ausgewählt wird im Vergleich zur Auswahl aus der Grundgesamtheit aller Spender (HCMV-seronegativ + HCMV-seropositiv + HCMV-Serostatus unbekannt) [47]. Die Einführung der generellen Leukozytendepletion senkte das Risiko einer transfusionsassoziierten HCMVÜbertragung mindestens auf das gleiche Niveau wie bei der ausschließlichen Verwendung HCMV-seronegativer Präparate ohne Leukozytendepletion [4953]. Ein Vergleich der Häufigkeit von HCMV-Virämie bei Empfängern nach Stammzelltransplantation zeigte keinen Unterschied zwischen den Patienten, die ausschließlich leukozytendepletiertes Blut erhielten und jenen, bei denen das Blutprodukt zusätzlich HCMV-Antikörper-negativ war [52]. Erythrozyten- und Thrombozytenkonzentrate haben daher eine hohe HCMV-Sicherheit.

Um insbesondere für die vulnerablen Empfängerpopulationen die HCMV-Sicherheit auch bei leukozytendepletierten zellulären Blutkomponenten noch weiter zu erhöhen, wird nach zusätzlichen Strategien gesucht, die das sehr geringe HCMVRestrisiko durch nicht zellgebundenes Virus oder Restzellkonzentrationen nach Leukozytendepletion noch weiter verringern. Hierzu sind verschiedene Strategien diskutiert worden. 
Während der seronegativen Fensterphase liegt die Viruskonzentration nach den bisher vorliegenden Daten meist unter $50 \mathrm{IU} / \mathrm{ml}$ im Plasma. In der frühen Serokonversionsphase werden die höchsten Viruskonzentrationen von bis zu 1600 IU/ $\mathrm{ml}$ im Plasma erreicht. Reaktivierungen/ Neuinfektion mindestens 12 Monate nach Serokonversionen (Langzeitserokonverter) sind bisher in Einzelfällen mit sehr niedrigen Viruskonzentrationen ähnlich wie in der Präserokonversionsphase beschrieben worden $[9,48]$.

Somit kämen als mögliche Strategien, die zusätzlich zur Leukozytendepletion eingesetzt werden könnten, die Verwendung von HCMV-Antikörper-negativen Spenden oder die Verwendung von Spenden von Personen, die mindestens seit 12 Monaten HCMV-serokonvertiert sind, in Frage. Außerdem könnte alternativ zu diesen Optionen zusätzlich zur Leukozytendepletion eine hochsensitive NAT möglichst aus Vollblut eingesetzt werden. Weitere aussagekräftige Studien dazu, ob und wenn ja in welchem Maße ein Sicherheitsgewinn durch zusätzliche Testung (Antikörper oder NAT) erreicht werden konnten, liegen jedoch nicht vor.

Bei Blutkomponenten, die nicht leukozytendepletiert werden können (z.B. Granulozyten- bzw. Lymphozytenkonzentrate), sollen Spenden von HCMV-seronegativen Spendern verwendet werden $[54,55]$. Zum Ausschluss unerkannt virämischer Spender in dieser Spenderpopulation (s.o.) kann der zusätzliche Einsatz einer NAT möglichst in Vollblut auf Abwesenheit von HCMV-Genom bei der Herstellung dieser Präparate für Hochrisikopatienten sinnvoll sein [9].

\subsection{Spenderbefragung}

Auf Grund der unspezifischen Symptomatik und häufig symptomloser Verläufe von HCMV-Infektionen ist eine gezielte Spenderbefragung nicht durchführbar.

\subsection{Spenderinformation und -beratung}

Sollte es im Rahmen der bedarfsweise durchgeführten HCMV-Spendertestung zum Nachweis einer HCMV-Infektion kommen, ist keine Spenderinformation notwendig. Angesichts der hohen Durchseuchung und der fehlenden Konsequen- zen für Immunkompetente ist eine spezifische Beratung nicht erforderlich.

\section{Empfänger}

\subsection{Prävalenz und Inzidenz von blutassoziierten Infektionen und Infektionskrankheiten bei Empfängerkollektiven}

Die altersabhängige Prävalenz von HCMV-Infektionen kann in Europa bis ca. $70 \%$ betragen. Nach Weber et al. [44] ist die Seroprävalenz bei polytransfundierten Patienten und intravenös Drogenabhängigen nicht gegenüber der Allgemeinbevölkerung erhöht. Frauen haben eine höhere Prävalenz als Männer. Angaben zu HCMV-Infektionen nach Transfusion wurden nach Einführung der generellen Leukozytendepletion von Erythrozyten- und Thrombozytenkonzentraten mit Ausnahme von Transplantatempfängern und einiger spezieller Patientenkollektive für Europa nicht veröffentlicht.

\subsection{Abwehrlage (Resistenz, vorhandene Immunität, Immunreaktivität, Alter, exogene Faktoren)}

Die zelluläre Immunantwort spielt nach heutigem Wissensstand eine wesentliche Rolle bei der Kontrolle der Virusinfektion und der Besserung der klinischen Symptome. Initial erfolgt die HCMV-Abwehr durch natürliche Killerzellen (NK-Zellen). Eine große Bedeutung haben auch die CD4- und CD8-positiven T-Zellen. Die spezifische Immunantwort, vermittelt durch MHC-I-restringierte CD8-positive zytotoxische T-Lymphozyten, aber auch MHC-II-restringierte T-Helfer-Lymphozyten, ist verantwortlich für die frühe Kontrolle der HCMV-Infektion und die Entwicklung einer langfristig vorhandenen protektiven Immunität [5]. Zunehmend geraten die $\gamma \delta$-T-Zellexpansion und regulatorische T-Zellen (Tregs) stärker in das Blickfeld [35]. Wichtiges Zielantigen für zytotoxische T-Lymphozyten sind das Tegument Phosphoprotein pp65 und die Epitope seiner Spaltprodukte. Weitere, für die Immunantwort wichtige Antigene sind z. B. pp150 und das Hüll-Glykoprotein B (gB) $[56,57]$. Gegen IE-Proteine gerichtete CD8-positive T-Lymphozyten sind für die Verhinderung einer HCMV-Er- krankung verantwortlich. Sie produzieren mehrere Zytokine, wobei IL-2 besonders wichtig für die Kontrolle/Terminierung der HCMV-Aktivität zu sein scheint. Bis zu $25 \%$ aller peripheren CD8-positiven TZellen können bei der Unterdrückung der viralen Replikation beteiligt sein. Schwere Krankheitsverläufe nach HCMV-Infektion treten fast ausschließlich bei Patienten mit gestörter zellulärer Immunität auf. CD4-positive T-Lymphozyten sind auch essentiell für die Induktion, die Vermehrung und den Erhalt von immunologischen Gedächtniszellen (memory cells) [58]. Die immunmodulierenden Eigenschaften von HCMV, wie z.B. die Herabregulation von MHC-I-Molekülen auf der Oberfläche infizierter Zellen, verhindern das Erkennen infizierter Zellen durch zytotoxische T-Lymphozyten und begünstigen die lebenslange Persistenz der Viren.

B-Zellen produzieren Antikörper gegen verschiedene HCMV-Antigene, darunter auch neutralisierende Antikörper z. B. gegen $g B, g H$ und einen pentameren Glykoproteinkomplex. Diese neutralisierenden Antikörper scheinen u.a. ebenfalls für die Terminierung der Virämie von Bedeutung zu sein. Wiederholte Infektionen können bei Personen mit erhöhter HCMV-Exposition wie z. B. bei wechselnden Sexualpartnern, bei Kontakt zu virämischen Patienten oder bei Betreuung virusausscheidender Personen auftreten. Bei diesen Personen wurden mit molekularbiologischen Methoden teilweise mehrere HCMV-Stämme nachgewiesen $[5,35,59]$.

\subsection{Schweregrad und Verlauf der Erkrankung}

Die primäre Infektion mit HCMV bei gesunden, immunkompetenten Personen verläuft in der Regel asymptomatisch. Wenn Symptome auftreten, manifestieren sie sich in Form eines grippe- oder mononukleoseähnlichen Krankheitsbildes mit Fieber, relativer oder absoluter Lymphozytose und/oder Pharyngitis, Lymphadenopathie, Hepatosplenomegalie und leichter Erhöhung der Transaminasen [4]. Demgegenüber kann die primäre Infektion bei kongenital infizierten Frühgeborenen, immunsupprimierten Patienten und HIV-Infizierten sowie nach Reaktivierung des latenten Virus, insbesondere 
bei Empfängern von allogenen Stammzelltransplantaten $\mathrm{zu}$ schwer verlaufenden bis tödlichen Erkrankungen führen $[60,61]$. Weitere Risikogruppen sind schwangere Frauen und stillende Mütter, die die Infektion auf das Kind übertragen können [11, 28, 62-64]. Durch die vorgeschriebene Leukozytendepletion zellulärer Blutkomponenten wird das HCMVÜbertragungsrisiko durch Transfusionen reduziert.

Für HCMV-seropositive Empfänger von autologen oder allogenen Stammzelltransplantaten bzw. Organtransplantaten und für Reifgeborene soll kein erhöhtes Risiko bestehen, an einer durch Transfusion übertragenen HCMV-Infektion zu erkranken (Übersichten in: $[11,65]$ ).

\subsection{Therapie und Prophylaxe}

Generell wird zwischen der Prävention einer HCMV-Infektion bzw. -Erkrankung und der Behandlung einer manifesten HCMV-Erkrankung unterschieden. Die Prävention umfasst prophylaktische, die Virusreplikation supprimierende Maßnahmen. Prophylaktische Maßnahmen werden bei Patienten begonnen, bei denen Virus und Erkrankung nicht nachweisbar sind. Als pre-emptive treatment wird die Behandlung mit antiviralen Substanzen bei Patienten definiert, bei denen eine HCMV-Virämie, nicht jedoch eine manifeste Erkrankung diagnostiziert wurde.

Wirksame Maßnahmen zur Vermeidung/Unterdrückung einer HCMV-Infektion sind die Anwendung antiviral wirksamer Substanzen sowie eine adoptive zelluläre Immuntherapie [7, 57, 58, 66-68]. Die klinische Bedeutung einer wirksamen Prävention der HCMVErkrankung (siehe 3.3) ist aufgrund ihrer hohen Morbidität und Mortalität bei den oben genannten Risikogruppen unumstritten. Bei Transplantation solider Organe setzt sich die teilweise organspezifische Prophylaxe mit antiviralen Substanzen unter Berücksichtigung des Serostatus von Spender und Empfänger durch [35, 69-73]. Bei der Stammzelltransplantation wird zunehmend präemptiv therapiert [40].

Die Gabe von intravenös applizierbaren Immunglobulinen (IVIG) oder HCMV-spezifischem Immunglobulin kommt als präventive Maßnahme nur in wenigen Einzelfällen in Betracht [35, 60, 61]. Studien, die die Wirksamkeit der IVIG belegen, sind auf Grund unterschiedlicher HCMV-Prophylaxeregimes nur eingeschränkt vergleichbar [62]. Im Rahmen von Stammzelltransplantationen ist die Gabe von IVIG zur Prävention einer HCMV-Infektion nicht indiziert [40, 65]. Die präventiven Maßnahmen sollten sich in jedem Fall an der Intensität der Immunsuppression, dem Risiko der Reaktivierung einer latenten HCMV-Infektion und der Verträglichkeit der antiviralen Substanzen orientieren [7, 10, 67].

Als antiviral wirksame Substanzen für die Prävention einer HCMV-Infektion bzw. für die Behandlung einer manifesten Erkrankung stehen die Nukleosidanaloga Ganciclovir, Valganciclovir und Cidofovir sowie das Pyrophosphatanalogon Foscarnet-Natrium zur Verfügung. Alle diese Substanzen hemmen die HCMV-DNA-Polymerase und somit die HCMV-Replikation. Sie müssen zum Erreichen therapeutischer Plasmakonzentrationen intravenös verabreicht werden und können z.T. schwerwiegende organspezifische unerwünschte Arzneimittelwirkungen auslösen (Ganciclovir: Myelotoxizität mit vorwiegend Neutro-, seltener Thrombozytopenie und bei langfristiger Verabreichung auch Anämie; Cidofovir: dosisabhängige Nephrotoxizität; Foscarnet-Natrium: Einschränkung der Nierenfunktion, Elektrolytverschiebungen). Oral kann Valganciclovir verabreicht werden. Durch Mutation vor allem im Bereich der UL97-Kinase und/oder UL54 DNA-Polymerase werden zunehmend unter Therapie insbesondere (Val)Ganciclovir Resistenzen und auch Kreuzresistenzen mit anderen Virostatika beobachtet. Dies erfordert die Entwicklung und Prüfung neuer antiviraler Substanzen, die sich teilweise bereits in der klinischen Prüfung (z.B. CMX001, Letermovir) befinden [74-80].

Die genannten Substanzen hemmen die Vermehrung von HCMV und können dadurch die klinische Symptomatik unterdrücken, jedoch die Viren nicht eliminieren. Durch die präemptive Gabe von Ganciclovir ist die Spätmanifestation der HCMV-Erkrankung (> 100 Tage nach Transplantation) gegenüber der Erkrankung in den ersten 100 Tagen nach Transplantation zu einem größeren Pro- blem geworden [81]. Der Einsatz des monoklonalen Antikörpers Alemtuzumab gegen CD52-positive Zellen im Rahmen des immunsuppressiven Regimes kann zu HCMV-Reaktivierungen führen, die durch die prophylaktische Gabe von geeigneten antiviralen Substanzen verhindert werden können [82].

Zusammenfassende Darstellungen der etablierten präventiven Maßnahmen einschließlich der Vor- und Nachteile der prophylaktischen bzw. präemptiven Therapie sowie aktuelle Behandlungsstrategien bei einer manifesten HCMV-Erkrankung finden sich bezogen auf verschiedene Transplantate und Patientengruppen in Übersichtsartikeln [35, 40, 83, 84].

\section{Impfung}

Die Entwicklung von Impfstoffen hat auch unter ökonomischen Aspekten hinsichtlich der Folgekosten von HCMV-Erkrankungen hohe Priorität. Eine Vakzine ist auf Grund des latenten Infektionszyklus und stammspezifischer Variationen, mangelnder Induktion eines Impfschutzes sowie weiteren Problemen bei klinischen Studien bisher noch nicht praxisreif [1, 85-87]. Im Licht neuer Erkenntnisse über die HCMV-Infektion hat sich die bisherige Strategie, neutralisierende Antikörper zu induzieren, als unzureichend erwiesen. Entscheidend ist die Stärkung der zellulären Abwehr. In Studien mit verschiedenen Kandidatvakzinen wird geprüft, ob das Impfziel einer langzeitwirksamen HCMV-spezifischen Immunantwort, z.T. unter Verwendung von Adjuvanzien, bei guter Langzeitsicherheit erreicht wird [59, 88-90].

\section{Adoptive Immuntherapie}

Die adoptive Immuntherapie mit HCMVspezifischen CD8-positiven zytotoxischen T-Zellen entwickelte sich in den letzten Jahren zunehmend als nebenwirkungsarme Therapieoption zu antiviralen Arzneimitteln [67, 68, 91]. Dabei wird dem Empfänger eine beim Spender bestehende Immunität (aktivierte T-Zellen und immunologische Gedächtniszellen) gegen ein bestimmtes Pathogen durch Transfusion übertragen. Eine Zusammenfassung der Meilensteine der adoptiven Immuntherapie haben die Arbeitsgruppen von van den Bosch bzw. Moss publiziert [57, 
58]. Möglich ist eine ex vivo Expansion von HCMV-spezifischen zytotoxischen T-Zellen bzw. CD4-positiven T-Zellen des seropositiven Stammzellspenders durch Restimulation mit HCMV-Epitopen. Es existiert eine Vielzahl von Protokollen zur ex vivo-Expansion der virusspezifischen T-Lymphozytenlinien [91-98]. Nachteilig ist neben dem Zeitbedarf eine verhältnismäßig geringe Überlebensrate der vermehrten Zellen durch Generierung eines proapoptotischen Moleküls (CD95) bei der Vermehrung. Die Selektion antigenspezifischer T-Zellen des Spenders durch HLA-Streptamere ermöglicht die Gewinnung ausreichender Zellzahlen für eine direkte Infusion [98-102]. Die gleichzeitige Isolation von CD4- und CD8-positiven T-Zellen durch Verfahren, welche anhand der sezernierten Zytokine die Zellpopulationen erkennen, findet überwiegend klinische Anwendung [57, 58].

Für die Therapie primärer HCMVInfektionen des Empfängers bei HCMVSeronegativität des Spenders wäre eine Impfung des Spenders zur Generierung von HCMV-spezifischen T-Lymphozyten denkbar, ein Verfahren, welches bislang nur in Studien eingesetzt wurde. [57, 92].

Wenn die Expansion virusspezifischer T-Lymphozyten bei HCMV-naiven Transplantatspendern nicht möglich ist, könnten nach ersten Forschungsergebnissen eventuell autologe T-Zellen nach Transfer von Genen, die T-Zellrezeptoren für die gewünschten viralen Peptide kodieren, als Basis für HCMV-spezifische T-Zelllinien dienen [58]. Eine weitere Möglichkeit ist die Gewinnung virusspezifischer T-Zellen von HLA-teilkompatiblen Fremdspendern - sogenannten thirdparty T-cell donors [103].

Die adoptive Immuntherapie ermöglicht vor allem nach Stammzelltransplantation die schnelle Rekonstitution der zellulären Abwehr gegen HCMV, umso mehr, da einige Transplantationsprotokolle eine T-Zelldepletion (z. B. bei haploidenter Transplantation) beinhalten. Einige Studien konnten die Effizienz in der Therapie und die Vermeidung des Auftretens von HCMV-Erkrankungen nachweisen [91, 92, 96, 100, 104-107]. Die Gabe von virusspezifischen Spender-T-Lymphozyten einige Wochen nach Transplantation senkt zusätzlich das Risiko des
Auftretens einer GVHD, ohne dass die Ursachen dafür bisher bekannt sind [58, 108]. Unklar ist derzeit, ob antigenspezifische CD4- oder CD8- positive T-Zellen einzeln oder gemeinsam appliziert werden sollten [105]. Erwähnenswert ist der Ansatz, die Expansion aus einem kleinen Aliquot des Stammzelltransplantats vorzunehmen und damit die logistisch oft problematische Wiedereinbestellung des Spenders zur Gewinnung virusspezifischer T-Zellen zu vermeiden [106, 107]. Die Fortschritte auf diesem Gebiet sind vielversprechend [109].

\section{5 Übertragbarkeit}

Für Stammzelltransplantierte lag das Gesamtrisiko für eine übertragene HCMVInfektion in den 1980er Jahren bei Verabreichung von Blutkomponenten ohne Berücksichtigung des HCMV-Antikörperstatus und ohne Leukozytendepletion im Bereich von $30 \%$ bis $60 \%[110,111]$. Eine HCMV-Übertragung auf seronegative Empfänger vor Einführung der Leukozytendepletion durch seropositives Blut wurde in 0,4 bis $4 \%$ der Empfänger beschrieben. Daraus folgt auch, dass die Infektion von der Mehrheit der seropositiven Spender nicht übertragen wird [11, 64, 112]. Durch HCMV-seronegative zelluläre Blutkomponenten wurde das Risiko einer HCMV-Infektion bei der Verabreichung nicht leukozytendepletierter Blutkomponenten verringert $[113,114]$. Die generelle Verwendung von leukozytendepletierten Blutkomponenten hat das Risiko ebenfalls gesenkt. Experimentell wurde in leukozytendepletierten Blutkomponenten eine Reduktion der zellgebundenen HCMV-DNA um ca. $3 \log _{10}$-Stufen gezeigt $[114,115]$. Die minimale infektiöse Dosis für eine HCMV-Infektion beim Menschen konnte bisher nicht definiert werden.

In einer multivariablen Analyse haben Nichols und Mitarbeiter festgestellt, dass die Wahrscheinlichkeit einer transfusionsassoziierten HCMV-Übertragung bei leukozytendepletierten Erythrozytenkonzentraten von HCMV-Antikörper-positiven Spendern höher ist als bei der Applikation HCMV-Antikörper-negativer Erythrozytenkonzentrate (Odds-Ratio 1,32 vs. 1,01). Überraschenderweise ließ sich das Ergebnis bei der Gabe von durch Aphere- se hergestellten Thrombozytenkonzentraten HCMV-Antikörper-positiver Spender nicht bestätigen [116]. Die Studienergebnisse sind auf Grund der angewandten Berechnungsmethoden nicht unumstritten [117]. Ronghe und Mitarbeiter konnten keinen Unterschied bzgl. der HCMV-Serokonversionsrate bei Patienten nach allogener Stammzelltransplantation finden, die entweder durch Apherese hergestellte leukozytendepletierte Thrombozytenkonzentrate oder HCMV-seronegative, nicht leukozytendepletierte Thrombozytenkonzentrate erhielten. Die Erythrozytensubstitution erfolgte mit nicht leukozytendepletierten, HCMV-seronegativen Erythrozytenkonzentraten [118]. Auch nach Einführung der generellen Leukozytendepletion wurden in 1 bis $3 \%$ der Transfusionsempfänger HCMV-Infektionen beschrieben [119]. Eine Metaanalyse der wenigen, oft Jahre zurückliegenden Studien zeigte keine Vorteile der HCMVAntikörpertestung gegenüber der Leukozytendepletion oder der Kombination aus beiden Strategien [52, 120]. In aktuellen Studien wird das Risiko einer transfusionsassoziierten Infektion nach Gabe von nicht auf HCMV-Antikörper untersuchten, leukozytendepletierten Blutkomponenten mit unter 1: 1.000 .000 angegeben $[121,122]$

\subsection{Häufigkeit der Applikation sowie Art und Menge der Blutprodukte}

Preiksaitis und Mitarbeiter haben für zelluläre Blutprodukte gezeigt, dass die nach Transfusion serokonvertierten Empfänger eine höhere Zahl von Einheiten (50 +/$38,9)$ erhalten hatten als nicht serokonvertierte Patienten $(23,7+/-15,3)$ [123]. Nicht nur die Menge der Blutprodukte, sondern auch die Grunderkrankung des Patienten beeinflussen das Infektionsrisiko [119].

Roback und Mitarbeiter untersuchten an Mäusen die minimale infektiöse Dosis zur Übertragung einer CMV-Infektion. Bei einer Applikation von $10^{4}$ Leukozyten pro $25 \mathrm{~g}$ Mausgewicht oder weniger wurde keine CMV-Übertragung beobachtet. Sie schlossen, dass die äquivalente Dosis beim Menschen bei $4 \times 10^{5}$ Leukozyten $/ \mathrm{kg}$ Körpergewicht liegen müsste. Damit würde bei Einhaltung der Grenze von $5 \times 10^{6}$ 
Leukozyten/Präparat das Risiko einer HCMV-Übertragung unwahrscheinlich werden [16].

Für therapeutisches Plasma sind bisher unabhängig von einer Leukozytendepletion oder Pathogeninaktivierung keine HCMV-Übertragungen beschrieben worden $[124,125]$. Das ist möglicherweise auf Instabilität des Virus bei Lagerungstemperaturen um $-20{ }^{\circ} \mathrm{C}$ zurückzuführen, worauf auch Erfahrungen mit eingefrorener Muttermilch hinweisen [20-23].

\section{Blutprodukte}

\subsection{Belastung des Ausgangsmaterials und Testmethoden}

Nach historischen Untersuchungen von Weber et al. sind etwa 2 bis $12 \%$ der anti-HCMV-positiven Blutspenden infektiös [126]. Sivakumaran et al. haben freie Viruspartikel im Blut HCMV-seropositiver Blutspender gefunden, insbesondere wenn die Proben länger standen und dadurch Zellen geschädigt wurden [127].

HCMV ist überwiegend zellassoziiert. Es wird geschätzt, dass $0,2 \%$ der im peripheren Blut vorhandenen Leukozyten eines HCMV-Antikörper-positiven Spenders latent infiziert sind, also HCMV-Genom enthalten. Mit sensitiven PCR-Methoden konnte die Arbeitsgruppe von Larsson bei allen serologisch positiven Spendern HCMV-Genom nachweisen [128]. Ein Antigennachweis für aktive Virusreplikation hingegen gelang nur bei etwa $6 \%$ der untersuchten HCMV-seropositiven Personen eines allerdings kleinen Blutspenderkollektivs [129].

Neue Untersuchungen mit verbesserten Techniken modifizieren die bisherigen Erkenntnisse. Im Zeitraum zwischen Infektion und erstmals nachweisbaren HCMV-Antikörpern (6 bis 8 Wochen) wird nach übereinstimmenden Untersuchungen eine Virämie beobachtet [47, 124, 130-132]. Eine Studie von Ziemann und Mitarbeitern mit einer sensitiven PCR konnte in $44 \%$ der von Serokonvertern stammenden Plasmen HCMV-DNA, z. T. bis zu einem Jahr nach Serokonversion nachweisen. Von 68 Spendern war eine Probe vor Serokonversion verfügbar. In zwei Fällen (2,9\%) konnte im Plasma HCMV-DNA 68 bzw. 98 Tage vor der ers- ten seropositiven Probe detektiert werden („Fensterphasenspende“). Bei 450 seit mehr als einem Jahr seropositiven Spendern (Langzeitserokonverter) konnte in keinem Fall HCMV-DNA im Plasma gefunden werden [47].

Ziemann und Mitarbeiter untersuchten 93 (Apherese-)Spender mit einem Spendeintervall von maximal 35 Tagen, bei denen erstmalig ein reaktives HCMVAntikörpertestergebnis erhalten wurde (48). Nur in 12 Fällen (13\%) konnte durch weitere HCMV-Antikörperteste und Immunoblotuntersuchungen eine Serokonversion bestätigt werden. Bei nicht bestätigbaren Serokonversionen konnte in keinem Fall HCMV-DNA im Plasma nachgewiesen werden. Damit wird die Aussagekraft eines mit einem HCMVAntikörper-Screeningtests erstmalig erhaltenen HCMV-Antikörpernachweises ohne weitere Bestätigungsdiagnostik in Frage gestellt. Bei 3 von 12 serokonvertierten Spendern wurden im Plasma der seronegativen Vorspende HCMV-DNA in einer Konzentration von unter 30 IU/ $\mathrm{ml}$ nachgewiesen. Weiterhin war von 10 der 12 serokonvertierten Spender die erste seropositive Probe auch HCMV-DNApositiv mit Konzentrationen bis zu 1600 IU/ml. Die höchsten Viruskonzentrationen wurden ungefähr zwei Wochen nach Serokonversion erreicht [48]. Diese Aussage wird auch durch Ergebnisse einer Studie mit aktiv gegen HCMV geimpften Frauen gestützt, in deren Körperflüssigkeiten zwei Wochen nach Serokonversion HCMV in der Zellkultur nachgewiesen wurde [133].

Die von Ziemann et al. 2007 [47] in die Diskussion gebrachte Verwendung von Blutkomponenten von Spendern mit einer mehr als 12 Monate zurück liegenden Serokonversion für HCMV-Risikopatienten fand große Beachtung [134]. In einer japanischen Studie mit $2400 \mathrm{HCMV}$-seropositiven Blutspendern unterschiedlicher Altersgruppen wurde mit einer sensitiven NAT nach HCMV-DNA in der zellulären Fraktion wie auch im Plasma gesucht. Bei 37 von 2400 Spendern (1,5\%) ließ sich in mehreren Untersuchungen HCMV-DNA in Zellen nachweisen, bei weiteren 4 Spendern ließ sich das initial positive NAT-Ergebnis nicht reproduzieren. HCMV-DNA wurde mit 6,6\% (6 von 91) am häufigsten bei Spendern in der frühen Serokonversion bei Anwesenheit von Anti-HCMVIgM nachgewiesen. Spender über 60 Jahre hatten häufiger HCMV-DNA mit höheren Konzentrationen im Blut, was von den Autoren auf eine höhere Reaktivierungsrate bei Alterung des Immunsystems zurückgeführt wurde. Nur bei 5 der 37 Proben wurde auch im Plasma HCMV nachgewiesen, wobei 1 Spender mit AntiHCMV-IgG und -IgM eine um mindestens 1 log-Stufe höhere Viruskonzentration hatte als die übrigen 4 Spender, die nur Anti-HCMV-IgG-positiv waren. Da die Viruskonzentrationen nicht in IU/ml angegeben wurden, ist eine direkte Vergleichbarkeit mit anderen Daten nicht möglich [31].

Ziemann und Mitarbeiter [9] fanden 2013 bei 22.904 Spenden in einer Region mit niedriger HCMV-Prävalenz einen größeren Anteil HCMV-DNA-positiver Spender mit höheren Viruskonzentrationen bei der Untersuchung von Vollblut im Vergleich zu Plasma. Insgesamt wurde bei 21 Spendern reproduzierbar HCMV-DNA nachgewiesen (0,09\%). Die höchsten Viruskonzentrationen (Vollblut mindestens $1000 \mathrm{IU} / \mathrm{ml}$ bzw. Plasma mindestens $100 \mathrm{IU} / \mathrm{ml}$ ) wurden bei 4 frisch serokonvertierten Spendern beobachtet. Die Mehrzahl der im Vollblut HCMV-DNA-positiven Spender war latent infiziert, während HCMV-DNA im Plasma vor allem bei frisch serokonvertierten Spendern gefunden wurde. Die Viruskonzentrationen von Spendern in der Präserokonversionsphase bzw. bei Langzeitserokonvertern waren niedriger und lagen im gleichen Bereich. Ohne HCMV-Diagnostik wurden im Vergleich zur Verwendung von HCMV-Antikörper-negativen negativen Spenden mehr HCMV-DNA-positive Spenden (0,09\% vs. $0,04 \%)$ mit bis zu siebenfach höherer Viruslast gefunden. Die Autoren haben auf Grund ihrer Resultate die maximal möglichen HCMV-DNA-Konzentrationen (IU/Präparat) in leukozytendepletierten Erythrozyten- und Thrombozytenkonzentraten unter Berücksichtigung des HCMV-Serostatus des Spenders abgeschätzt (• Tab. 1).

Frei im Plasma vorhandenes HCMV trägt in hohem Maß zur Gesamtviruslast bei. Wegen einer ineffizienteren Infektion 
Tab. 1 Maximal hochgerechnete HCMV-Viruslast (IU/Präparat) in leukozytendepletierten Erythrozyten- und Thrombozytenkonzentraten (mod. nach Ziemann et al.) [9], Verwendet wurde eine NAT mit einer unteren Nachweisgrenze (LOD, limit of detection) von 12 IU/ml

\begin{tabular}{lllll}
\hline Blutkomponenten & $\begin{array}{l}\text { Nicht auf HCMV- } \\
\text { Antikörper getestete } \\
\text { Spender }\end{array}$ & $\begin{array}{l}\text { HCMV-Antikörper- } \\
\text { negative Spender }\end{array}$ & $\begin{array}{l}\text { Langzeit seropositive } \\
\text { Spender }\end{array}$ & $\begin{array}{l}\text { Plasma NAT-negative } \\
\text { Spender }\end{array}$ \\
\hline $\begin{array}{l}\text { a) Zellgebundenes HCMV } \\
\text { EK }\end{array}$ & 300 & 50 & 60 & 60 \\
TK (buffy coat) & 100 & 20 & 20 & 20 \\
TK (Apherese) & 3000 & 400 & 600 & 600 \\
b) HCMV im Plasma & & & $<600$ & $<200$ \\
EK (18 ml Plasma) & 10.000 & 1.000 & $<2000$ bis 9000 & $<700$ bis 4000 \\
TK (60 bis 300 ml Plasma) & 40.000 bis 200.000 & 4000 bis 20.000 &
\end{tabular}

im Vergleich zum Zell-Zell-Kontakt kann daraus möglicherweise nicht unmittelbar auf eine höhere Infektiosität geschlossen werden [9].

Für Plasma zur Fraktionierung ist eine Testung auf HCMV nicht notwen$\operatorname{dig}$ (s. 3.6).

Als Testmethoden bieten sich die oben (s. 1.4) genannten Verfahren vor allem zur Identifizierung von Spenden mit verhältnismäßig hohen Viruskonzentrationen in der Serokonversionsphase an. Beim derzeitigen Wissenstand ist keine Präferenz für eine Methode sicher belegbar [135]. Nach Verfügbarkeit des WHO-Standards für HCMV-DNA, kommerzieller Assays und Ringversuche ist eine höhere Standardisierbarkeit und Vergleichbarkeit der NAT-Methoden gegeben [136-138].

\subsection{Möglichkeiten zur Abtrennung und Inaktivierung von Infektionserregern}

Die Ergebnisse von Studien zur Äquivalenz der Leukozytendepletion bzw. der Applikation von seronegativem Blut sind widersprüchlich. Einerseits wird beschrieben, dass die Leukozytendepletion der Verwendung HCMV-seronegativer, nicht leukozytenreduzierter Blutkomponenten äquivalent ist $[55,62,63,116$, 119, 139-146]. Neue Studienergebnisse belegen, dass frisch serokonvertierte Spender die höchsten Viruskonzentrationen im Verlauf einer HCMV-Infektion haben. Diese Spender waren klinisch asymptomatisch und wurden ohne HCMV-Diagnostik nicht erkannt [9, 31, 47, 48]. Die Leukozytendepletion für Erythrozyten- und Thrombozytenprä- parate ist in Deutschland vorgeschrieben, so dass zellassoziiertes HCMV deutlich abgereichert wird, ohne jedoch freies HCMV im Plasma reduzieren zu können [48]. Weder durch Leukozytendepletion noch durch ausschließliche Verwendung von Antikörper-negativen Blutkomponenten ist es möglich, die in einer Präserokonversionsphase gespendeten, virämischen Blutkomponenten von der Transfusion auszuschließen [147] (siehe 2.3).

Bei der Herstellung von Plasmaderivaten wird durch die Herstellungsverfahren HCMV zuverlässig inaktiviert [148-151]. Da HCMV eine Lipidhülle besitzt, führen alle Verfahren, die die Lipidhülle angreifen (z. B. S/D-Verfahren), zu einer Inaktivierung von HCMV. Ebenso wird HCMV durch Hitzebehandlung (z. B. Pasteurisierung) inaktiviert. Es gibt weiterhin Filter, die das 150-200 nm große HCMV zurückhalten und zur Herstellung von Plasmaderivaten eingesetzt werden. Eine HCMV-Übertragung durch Plasmaderivate kann nach jetzigem Kenntnisstand ausgeschlossen werden.

Es werden verschiedene Strategien verfolgt, Viren wie HCMV und andere Pathogene wie Bakterien und Parasiten in Blut und Blutkomponenten wie Erythrozyten- und Thrombozytenkonzentraten zu inaktivieren. Für die Inaktivierung können photodynamische Behandlungen für Erythrozytenkonzentrate und photochemische Verfahren für Thrombozytenkonzentrate eingesetzt werden. Für eine Vielzahl von zellfreien und zellassoziierten Viren, Bakterien und Parasiten wurde dabei die Wirksamkeit der Inaktivierungsverfahren belegt und man kann davon ausgehen, dass HCMV ebenfalls inaktiviert wird [152-158].

Die Verwendung von pathogeninaktivierten zellulären Blutkomponenten wird teilweise kontrovers diskutiert [159]. Um die Wirksamkeit und Verträglichkeit von pathogeninaktivierten Thrombozytenpräparaten zu belegen, wurden in multizentrischen klinischen Studien die Vor- und Nachteile untersucht und gezeigt, dass diese Präparate grundsätzlich sicher und verträglich sind. Jedoch sollte längerfristig die Anwendung solcher Präparate wissenschaftlich begleitet werden [150, 160]. Verfahren zur Inaktivierung von Pathogenen in Erythrozytenpräparaten sind noch in Entwicklung und müssen in klinischen Studien weiter untersucht werden $[155$, 158].

\subsection{Praktikabilität und Validierbarkeit der Verfahren zur Elimination/Inaktivierung von Infektionserregern}

Auf die Bedeutung der Leukozytendepletion für die Sicherheit zellulärer Komponenten wurde bereits unter 4.2 eingegangen. HCMV kann nicht direkt zum experimentellen Nachweis der Virussicherheit der Plasmaderivate eingesetzt werden, da es nicht in hohen Konzentrationen in Zellkultur zu züchten und nur schwierig zu titrieren ist. Antikörper im humanen Plasma würden außerdem mit dem Virus reagieren und die Ergebnisse beeinflussen. Deshalb werden zur Untersuchung der Verfahren animale Herpesviren als Modellviren verwendet [148, $161,162]$. Das am häufigsten verwendete Herpesvirus ist das Pseudorabies-Virus (Schweineherpesvirus Typ 1, SHV-1). Es 
ist in seinen Eigenschaften, z. B. Thermostabillität und Empfindlichkeit gegenüber Lipidlösungsmitteln und niedrigen $\mathrm{pH}$ Werten, vergleichbar mit HCMV.

\section{Bewertung}

HCMV-Infektionen weisen bei gesunden, immunkompetenten Personen eine geringe Pathogenität auf und rufen, wenn überhaupt, nur leichte Krankheitssymptome hervor. HCMV führt zu latenten (persistierenden) Infektionen, wobei Reaktivierungen mit Virusvermehrung auftreten können (mit und ohne Symptomatik). Bei Immuninkompetenten werden jedoch häufig schwere HCMV-bedingte Erkrankungen beobachtet. Obwohl eine antivirale Chemotherapie und in einigen Fällen eine adoptive Immuntherapie möglich ist, sollte eine Übertragung von HCMV durch Blutkomponenten bei Schwangeren, Feten, Frühgeborenen, Patienten mit angeborenem oder erworbenem Immundefekt (AIDS) sowie Organ- und Stammzelltransplantierten so weit wie möglich vermieden werden.

Eine Übertragung von HCMV durch therapeutisches Frischplasma ist nicht bekannt. Für Plasmaderivate (z. B. Gerinnungsfaktoren, Immunglobuline, Albu$\min$ ) ist eine Übertragung auf Grund der eingesetzten Virusinaktivierungs-/eliminierungsverfahren ausgeschlossen.

Für Thrombozytenkonzentrate verfügbare Pathogeninaktivierungsverfahren (z.B. mit Amotosalen, Riboflavin) können das HCMV-Übertragungsrisiko ohne Berücksichtigung des HCMV-Status des Spenders reduzieren. Für Erythrozytenkonzentrate existieren derzeit noch keine zertifizierten Pathogeninaktivierungsverfahren.

Die in Deutschland obligate Leukozytendepletion für Erythrozyten- und Thrombozytenkonzentrate minimiert das Risiko einer HCMV-Übertragung durch diese Blutkomponenten.

Um das geringe Restrisiko einer HCMV-Übertragung durch zusätzliche Testung der Spender insbesondere für vulnerable Patientengruppen noch weiter $\mathrm{zu}$ reduzieren, wurden verschiedene Testoptionen diskutiert. Grundsätzlich käme die Verwendung HCMV-Antikörper-negativer Spenden, HCMV-Antikörper-positiver Spenden ab einem Jahr nach Serokon- version oder die HCMV-NAT aus Vollblut in Betracht. Ob und wenn ja in welchem Ausmaß eine zusätzliche Testung von Spenden die HCMV-Sicherheit von zellulären Blutkomponenten weiter erhöht, ist nur in wenigen Studien untersucht worden. Diese wenigen aktuellen Daten zeigten keinen Vorteil gegenüber der ausschließlichen Leukozytendepletion. Bei der Applikation von nicht leukozytendepletierbaren zellulären Blutkomponenten, z.B. Granulozytenkonzentraten, sollten entsprechend nationaler und internationaler Empfehlungen bei HCVM-seronegativen Empfängern HCMV-Antikörper negative Spenden angewendet werden. Zum Ausschluss unerkannt virämischer HCMV-Antikörper-negativer Spender kann der zusätzliche Einsatz einer hochsensitiven NAT auf Abwesenheit von HCMV-Genom bei der Herstellung dieser Präparate für Hochrisikopatienten erwogen werden. Da HCMV überwiegend zellgebunden vorliegt, sollte die HCMV-NAT in diesen Fällen möglichst unter Verwendung von Vollblut des Spenders durchgeführt werden.

Eine optimale Strategie zur weiteren Risikominimierung einer transfusionsassoziierten HCMV-Infektion lässt sich aus dem derzeitigen Kenntnisstand nicht ableiten.

Forschungsbedarf besteht hinsichtlich der Ermittlung der minimalen Infektionsdosis als Voraussetzung zur weiteren Optimierung der Teststrategie.

Dieses Papier wurde fertig gestellt am 06.03.2017 und vom Arbeitskreis Blut am 17.03.2017 verabschiedet. Es ersetzt die Arbeit aus dem Jahr 2010 (Bgbl 2010; 53:973-983). Es wurde erarbeitet von den Mitgliedern der Untergruppe „Bewertung blutassoziierter Krankheitserreger" des Arbeitskreises Blut: Dr. Volkmar Schottstedt, Prof. Dr. Martin Aepfelbacher, Dr. Ursula Bauerfeind, PD Dr. Isabelle Bekeredjian-Ding, PD Dr. Dr. Johannes Blümel, Prof. Dr. Reinhard Burger, Prof. Dr. Markus Funk, Dr. Albrecht Gröner, Prof. Dr. Lutz Gürtler, Dr. Margarethe Heiden, Prof. Dr. Martin Hildebrandt, Prof. Dr. Dr. Bernd Jansen, Dr. Ruth Offergeld, Prof. Dr. Georg Pauli, Dr. Uwe Schlenkrich, Prof. Dr. Rainer Seitz, PD Dr. Dorothea Stahl, Dr. Johanna Strobel, Dr. Hannelore Willkommen.

\section{Literatur}

1. Hambrecht $\mathrm{K}$, Jahn $\mathrm{G}$ (2007) Humanes Cytomegalovirus und kongenitale Infektion. Bundesgesundheitsbl-GesundheitsforschGesundheitsschutz 50:1379-1392

2. Klein M, Schoppel K, Amvrossiadis N, Mach M (1999) Strain-specific neutralization of human cytomegalovirus isolates by human sera. J Virol 73:878-886

3. Fields BN, Knipe DM, Howley PM (Hrsg) (2013) Virology. 6th edition. Wolters Kluwer Health/ Lippincott Williams \& Wilkins, Philadelphia

4. Mandell GL, Bennett JE, Dolin R (2010) Principles and practice of infectious diseases. 7th edition. Churchill Livingstone/Elsevier, Philadelphia

5. Van der Meer JTM, Drew WL, Bowden RA et al (1996) Summary of the international consensus symposium on advances in the diagnosis, treatment and prophylaxis of cytomegalovirus infection. Antiviral Res 32:119-140

6. Fornara O, Odeberg J, Khan Z et al (2013) Human cytomegalovirus particles directly suppress CD4 T-lymphocyte activation and proliferation. Immunobiol 218:1034-1040

7. De Jong MD, Galasso GJ, Gazzard B et al (1998) Summary of the II. international symposium on cytomegalovirus. Antiviral Res 39:141-162

8. Freemann RB Jr (2009) The 'indirect' effects of cytomegalovirus infection. Am J Transpl 9:2453-2458

9. Ziemann M, Juhl D, Görg S, Hennig H (2013) The impact of donor cytomegalovirus DNA on transfusion strategies for at-risk-patients. Transfusion 53:2183-2187

10. Fishman JA, Rubin RH (1998) Infection in organtransplant recipients. N Engl J Med 338:17411751

11. Petz LD, Swisher SN (Hrsg) (1996) Clinical Practice of Transfusion Medicine. Third Edition. Churchill Livingstone, New York

12. Taylor-Wiedeman J, Sissons JG, Borysiewicz LK Sinclair JH (1991) Monocytes are a major site of persistence of human cytomegalovirus in peripheral blood mononuclear cells. J Gen Virol 72:2059-2064

13. Movassagh M, Gozlan J, Senechal B, Baillou C, Petit JC, Lemoine FM (1996) Direct infection of CD34+ progenitor cells by human cytomegalovirus: Evidence for inhibition of hematopoiesis and viral replication. Blood 88:1277-1283

14. Zhuravskaya T, Maciejewski JP, Netski DM, Bruening E, Mackintosh FR, Jeor StS (1997) Spread of human cytomegalovirus (HCMV) after infection of human hematopoietic progenitor cells: model of HCMV latency. Blood 90:2482-2491

15. Larsson S, Soderberg-Naucler C, Moller E (1998) Productive cytomegalovirus (CMV) infection exclusively in CD13-positive peripheral blood mononuclear cells from CMV-infected individuals: implications for prevention of CMV transmission. Transplantation 65:411-415

16. Roback JD, Su L, Zimring JC, Hillyer CD (2007) Transfusion-transmitted cytomegalovirus: Lessons from a murine model. Transf. Med Rev 21:26-36

17. Bolovan-Fritts CA, Mocarski ES, Wiedemann JA (1999) Peripheral blood CD14(+) cells from healthy subjects carry a circular conformation of latent cytomegalovirus genome. Blood 93:394-398 
18. Meier J, Lienicke U, Tschirch E, Krüger DH, Wauer RR, Prösch S (2005) Human cytomegalovirus reactivation during lactation and mother-to-child transmission in preterm infants. J Clin Microbiol 43:1318-1324

19. Trincado DE, Rawlinson WD (2001) Congenital and perinatal infections with cytomegalovirus. J Paed Child Health 37:187-192

20. Lanzieri TM, Dollard SC, Josephson CD, Schmid DS, Bialek SK (2013) Breast milk-acquired cytomegalovirus infection and disease in VLBW and premature infants. Pediatrics 131:e1937-1945

21. Maschmann J, Hamprecht $K$, Weissbrich B, Dietz K, Jahn G, Speer CP (2006) Freeze-thawing of breast milk does not prevent cytomegalovirus transmission to a preterm infant. Arch. Dis Child Fetal Neonatal. Ed 91:F288-290

22. Lee $\mathrm{CH}$, Enright A, Benitz WE, Madan A (2007) Postnatal cytomegalovirus infection from frozen breast milk in preterm, low birth weight infants. Ped Infect Dis J 26:276-277

23. Forsgren M (2004) Cytomegalovirus in breast milk: Reassessment of pasteurization and freezethawing. Pediatr Res 56:526-528

24. Stocchi R, Ward KN, Fanin R, Baccarani M, Apperley JF (1999) Management of human cytomegalovirus infection and disease after allogenenic bone marrow transplantation. Haematologica 84:71-79

25. Travi G, Pergam SA (2013) Cytomegalovirus pneumonia in hematopoietic stem cell recipients. J Intensive Care Med 29:200-212

26. Stratta RJ, Pietrangeli C, Baillie GM (2010) Defining the risks for cytomegalovirus infection disease after solid organ transplantation. Pharmacotherapy 30:144-157

27. Jacobson MA, Zegans M, Pavan PR et al (1997) Cytomegalovirus retinitis after initiation of highly active antiretroviral therapy. Lancet 349:1443-1445

28. Przepiorka D, LeParc GF, Werch J, Lichtiger B (1996) Prevention of transfusion-associated cytomegalovirus infection. Am J Clin Pathol 106:163-169

29. Krech U (1973) Complement-fixing antibodies against cytomegalovirus in different parts of the world. Bull World Health Organ 49:103-106

30. Lamberson HV, Dock NL (1992) Prevention of transfusion-transmitted cytomegalovirus infection. Transfusion 32:196-198

31. Furui $Y$, Satake M, Hoshi Y, Uchida S, Suzuki K Tadokoro K (2013) Cytomegalovirus (CMV) seroprevalence in Japanese blood donors and high detection frequency of CMV DNA in elderly donors. Transfusion 53:2190-2197

32. Staras SAS, Flander WD, Dollard SC, Pass RF, McGowan JE, Cannon MJ (2008) Influence of sexual activity on cytomegalovirus seroprevalence in the United States, 1988 - 1994. Sex Transm Dis 35:472-479

33. Reimer K, Meisel H (1996) Humanes Zytomegalievirus. In: Porstmann T (Hrsg) Virusdiagnostik. Diagnostische Bibliothek, Bd. 1. Blackwell Wissenschafts-Verlag, Berlin/Wien

34. Mertens T, Haller OA, Klenk HD (Hrsg) (2004) Zytomegalievirus (CMV). In: Diagnostik und Therapie von Viruskrankheiten. Leitlinien der Gesellschaft für Virologie. München. Urban \& Fischer, Jena

35. Kotton CN, Kumar D, Caliendo AM et al (2013) Updated international consensus guidelines on the management of cytomegalovirus in solid-organ transplantation. Transplantation 96:333-360

36. Preiksaitis JK, Brennan DC, Fishman J, Allen U (2005) Canadian Society of Transplantation consensus workshop on cytomegalovirus management in solid organ transplantation final report. Am J Transpl 5:218-227

37. Subramanian V (2008) Distinguishing primary CMV infection from reactivation of latent infection. Dig Dis Sci 53:140

38. Lazzarotto T, Guerra B, Lanari M, Gabrielli L, Landini MP (2008) New advances in the diagnosis of congenital cytomegalovirus infection. J Clin Virol 41:192-197

39. Ritter M, Schmidt T, Dirks J et al (2013) Cytomegalovirus-specific T cells are detectable in early childhood and allow assignment of the infection status in children with passive maternal antibodies. Eur J Immunol 43:1099-1108

40. Emery VC, Zuckerman M, Jackson G et al (2013) Management of cytomegalovirus infection in haemopoietic stem cell transplantation. Brit J Haematol 162:25-39

41. Bringmann G (1990) Bedeutung der Zytomegalievirusinfektion in der Transfusionsmedizin. Inaugural-Dissertation. Medizinische Fakultät der Heinrich-Heine-Universität, Düsseldorf

42. Hecker M, Qui D, Marquardt K, Bein G, Hackstein $\mathrm{H}$ (2004) Continuous cytomegalovirus seroconversion in a large group of healthy blood donors. Vox Sang 86:41-44

43. Kothari A, Ramachandran VG, Gupta P, Singh B, Talwar V (2002) Seroprevalence of cytomegalovirus among voluntary blood donors in Dehli, India. J Health Popul Nutr 20:348-351

44. Weber B, Doerr HW (1994) Diagnosis and epidemiology of transfusion-associated human cytomegalovirus infection: recent developments. Infusionsther Transfusionsmed 21(suppl 1):32-39

45. Galea G, Urbaniak SJ (1993) Cytomegalovirus studies on blood donors in north-east Scotland and a review of UK data. Vox Sang 64:24-30

46. Schennach $H$, Hessenberger $G$, Mayersbach $P$, Schönitzer D, Fuchs D (2002) Acute cytomegalovirus infections in blood donors are indicated by increased serum neopterin concentrations. Med Microbiol Immunol 191:115-118

47. Ziemann $M$, Krueger $S$, Maier $A B$, Unmack $A$, Goerg S, Hennig H (2007) High prevalence of cytomegalovirus DNA in plasma samples of blood donors in connection with seroconversion. Transfusion 47:1972-1983

48. Ziemann M, Heuft HG, Frank K, Kraas S, Görg S, Hennig H (2013) Window period duration during primary cytomegalovirus infection and risk of transfusion-transmitted infections. Transfusion 53:1088-1094

49. Wu Y, Zou S, Cable R et al (2010) Direct assessment of cytomegalovirus transfusiontransmitted risk after universal leucoreduction. Transfusion 50:776-786

50. Thiele T, Krüger W, Zimmermann K et al (2011) Transmission of cytomegalovirus (CMV) infection by leucoreduced blood products not tested for CMV antibodies: A single-center prospective study in high-risk patients undergoing allogeneic hematopoietic stem cell transplantation. Transfusion 51:2620-2626

51. Nash T, Hoffmann S, Butch S, Davenport R, Cooling L (2012) Safety of leucoreduced cytomegalovirus (CMV)-untested components in
CMV-negative allogeneic human progenitor cell transplant patients. Transfusion 52:2270-2272

52. Kekre N, Tokessy M, Mallick R et al (2013) Is cytomegalovirus testing of blood products still needed for hematopoietic stem cell transplant recipients in the era of universal leucoreduction? Biol Blood Marr Transpl 19:1719-1724

53. Richtlinien zur Gewinnung von Blut und Blutbestandteilen und zur Anwendung von Blutprodukten (Hämotherapie) vom 4. Mai 2010. Bundesanzeiger Nr. 101a vom 9. Juli 2010

54. Querschnitts-Leitlinien (BÄK) zur Therapie mit Blutkomponenten und Plasmaderivaten (2014) http://www.bundesaerztekammer.de/ downloads/QLL_Haemotherapie_2014.pdf. Zugegriffen 31. Juli 2017

55. SaBTO Position Statement: Cytomegalovirus tested blood components. 2012 https://www. gov.uk/government/uploads/system/uploads/ attachment data/file/215125/dh_133086.pdf Zugegriffen 31. Juli 2017

56. Riddell SR, Greenberg PD (1997) T cell therapy of human CMV and EBV infection in immunocompromised hosts. Rev Med Virol 7:181-192

57. van den Bosch GA, Ponsaerts $P$, Vanham $G$, van Bockstaele DR, Berneman ZN, van Tendeloo VF (2006) Cellular immunotherapy for cytomegalovirus and HIV-1 infection. J Immunother 29:107-121

58. Moss P, Rickinson A (2005) Cellular immunotherapy for viral infection after HSC transplantation. Nat Rev 5:9-20

59. Dasari V, Smith C, Khanna R (2013) Recent advances in designing an effective vaccine to prevent cytomegalovirus-associated clinical diseases. Expert Rev Vaccines 12:661-676

60. Nigro G, Adler SP, La Torre R, Best AM (2005) Passive immunization during pregnancy for congenital cytomegalovirus infection. N Engl J Med 353:1350-1362

61. Aslam M, Anderson JL, Guglietti D, Cardwell D (2007) CMV-induced neonatal thrombocytopenia: a case report and review of the literature. Am J Perinat 24:429-434

62. Bonaros N, Mayer B, Schachner T, Laufer G, Kocher A (2007) CMV-hyperimmune globulin for preventing cytomegalovirus infection and disease in solid organ transplant recipients: a meta-analysis. Clin Transplant 22:89-97

63. Pamphilon DH, Rider JR, Barbara JA, Williamson LM (1999) Prevention of transfusion-transmitted cytomegalovirus infection. Transfus Med 9:115-123

64. Müller-Eckhardt C, Kiefel V (Hrsg) (2010) Transfusionsmedizin, 4. Aufl. Springer, Berlin

65. Ljungman P, Aschan J, Lewensohn-Fuchs I et al (1998) Results of different strategies for reducing cytomegalovirus-associated mortality in allogeneic stem cell transplant recipients. Transplantation 66:1330-1334

66. Vogel JU, Scholz M, Cinatl J Jr (1997) Treatment of cytomegalovirus diseases. Intervirology 40:357-367

67. Balfour HH (1999) Antiviral Drugs. N Engl J Med 340:1255-1268

68. Micklethwaite KP, Clancy L, Sandher U et al (2008) Prophylactic infusion of cytomegalovirus specific cytotoxic T-lymphocytes stimulated with Ad5f35pp65 gene modified dendritic cells following allogenic haemopoietic stem cell transplantation. Blood 112:3974-3981

69. Hodson EM, Jones CA, Webster AC et al (2005) Antiviral medications to prevent cytomegalovi- 
rus disease and early death in recipients of solidorgan transplants: a systematic review of randomised controlled trials. Lancet 365:2105-2115

70. Diaz MAM, Romero NC, Sánchez-Fructuoso A et al (2007) Cytomegalovirus infection in seronegative patients treated with prophylaxis: casecontrolled study. Transpl Proc 39:2231-2232

71. Fishman JA, Emery V, Freeman R et al (2007) Cytomegalovirus in transplantation - challenging the status quo. Clin Transplant 21:149-158

72. Fallatah SM, Marquez MA, Bazerbachi F et al (2013) Cytomegalovirus infection post-pancreaskidney transplantation - results of antiviral prophylaxis in high-risk patients. Clin Transplant 27:503-509

73. Meije Y, Fortún J, Len Ó et al (2014) Prevention strategies for cytomegalovirus disease and long-term outcomes in the high-risk transplant patient (D+/R-): experience from the RESITRAREIPI cohort. Transpl Infect Dis 16:387-396

74. da Cunha-Bang C, Kirkby N, SØnderholm M et al (2013) The time course of development and impact from viral resistance against ganciclovir in cytomegalovirus infection. Am J Transpl 13:458-466

75. Yeon Choi K, Sharon B, Balfour HH Jr, Belani K, Pozos TC, Schleiss MR (2013) Emergence of antiviral resistance during oral valganciclovir treatment of an infant with congenital cytomegalovirus (CMV) infection. J Clin Virol 57:356-360

76. Komatsu TE, Pikis A, Naeger LK, Harrington $P$ (2014) Resistance of human cytomegalovirus to ganciclovir/valganciclovir: a comprehensive review of putative resistance pathways. Antivir Res 101:12-25

77. Ljungman $P$ (2013) CMV: a warrior against leukemia? Transplantation 122:1101-1102

78. Marty FM, Drew J, Winston DJ et al (2013) CMX001 to prevent cytomegalovirus disease in hematopoietic-cell transplantation. $\mathrm{N}$ Engl J Med 369:1227-1236

79. Chemaly RF, Ullmann AJ, Stoelben S et al (2014) Letermovir for cytomegalovirus prophylaxis in hematopoietic-cell transplantation. N Engl J Med 370:1781-1789

80. Lischka P, Michel D, Zimmermann H (2016) Characterization of Cytomegalovirus breakthrough events in a phase 2 prophylaxis trial of Letermovir (AIC246, MK8228). J Infect Dis 213:23-30

81. Asano-Mori Y, Kanda Y, Oshima K et al (2009) Clinical features of late cytomegalovirus infection after hematopoietic stem cell transplantation. Int J Hematol 87:310-318

82. O'Brien S, Ravandi F, Riehl T et al (2008) Valganciclovir prevents cytomegalovirus reactivation in patients receiving alemtuzumab-based therapy. Blood 111:1816-1819

83. Schleiss MR (2008) Congenital cytomegalovirus infection: update on management strategies. Curr Treat Opt Neur 10:186-192

84. Kowalsky S, Arnon R, Posada R (2013) Prevention of cytomegalovirus following solid organ transplantation: A literature review. Ped Transpl 17:499-509

85. Khanna R, Diamond DJ (2006) Human cytomegalovirus vaccine: time to look for alternative options. Trends Mol Med 12:26-33

86. Steininger C (2007) Clinical relevance of cytomegalovirus infection in patients with disorders of the immune system. Clin Microbiol Inf 13:953-963

87. Adler SP (2008) Human CMV vaccine trials: what if CMV caused a rash? J Clin Virol 41:231-236
88. Kharfan-Dabja MA, Boeckh M, Wilck MB et al (2012) A novel therapeutic cytomegalovirus DNA vaccine in allogeneic haemopoietic stemcell transplantation: a randomized, double blind, placebo-controlled, phase 2 trial. Lancet Infect Dis 12:290-299

89. Rieder F, Steininger C (2014) CMV vaccine: phase II clinical trial results. Clin Microbiol Inf Suppl. 5(20):95-102

90. Krause PR, Bialek SR, Boppana SB et al (2013) Priorities for CMV vaccine development. Vaccine 17:4-10

91. Einsele H (2003) Immunotherapy of cytomegalovirus infection after stem-cell transplantation: a new option? Lancet 362:1343-1344

92. Einsele H, Roosnek E, Rufer $\mathrm{N}$ et al (2002) Infusion of cytomegalovirus (CMV)-specific T cells for the treatment of CMV infection not responding to antiviral chemotherapy. Blood 99:3916-3922

93. La Rosa C, Wang Z, Lacey SF et al (2006) In vitro expansion of polyclonal T-cell subsets for adoptive immunotherapy by recombinant modified vaccinia Ankara. Exp Hematol 34:497-507

94. Melenhorst JJ, Solomon SR, Shenoy A et al (2006) Robust expansion of viral antigenspecific CD4+ and CD8+T cells for adoptive T cell therapy using gene-modified activated $T$ cells as antigen presenting cells. J Immunother 29:436-443

95. Paine A, Oelke M, Blasczyk R, Elz-Vesper B (2007) Expansion of human cytomegalovirus-specific T lymphocytes from unfractionated peripheral blood mononuclear cells with artificial antigenpresenting cells. Transfusion 47:2143-2152

96. Micklethwaite K, Hansen A, Foster A et al (2007) Ex vivo expansion and prophylactic infusion of CMV-pp65 peptide-specific cytotoxic TLymphocytes following allogenic hematopoietic stem cell transplantation. Biol Blood Marrow Transplant 13:707-714

97. Bao L, Sun Q, Lucas KG (2007) Rapid generation of CMV pp65-specific T cells for immunotherapy. J Immunother 30:557-561

98. Peggs K, Verfuerth S, Mackinnon S (2001) Induction of cytomegalovirus (CMV)-specific T-cell responses using dendritic cells pulsed with $C M V$ antigen: a novel culture system free of live CMV virions. Blood 97:994-1000

99. Szmania S, Galloway A, Bruorton M et al (2001) Isolation and expansion of cytomegalovirusspecific cytotoxic $T$ lymphocytes to clinical scale from a single blood draw using dendritic cells and HLA-tetramers. Blood 98:505-512

100. Cobbold M, Khan N, Pourgheysari B et al (2005) Adoptive transfer of cytomegalovirus specific CTL to stem cell transplant patients after selection by HLA-peptide tetramers. J Engl Med 202:379-386

101. Roback JD (2006) Vaccine-enhanced donor lymphocyte infusion (veDLI). Hematology 2006:486-491

102. Sakagawa $\mathrm{H}$, Azuma H, Fujihara M, Ikeda H (2006) Clinical-scale expansion of human cytomegalovirus-specific cytotoxic T lymphocytes from peripheral blood mononuclear cells requiring single-peptide stimulation and feeder cells but not additional antigen-presenting cells. Transfusion 46:516-522

103. Eiz-Vesper B, Maecker-Kolhoff, Blasczyk R (2013) Adoptive immunotherapy from third-party donors: characterization of donors and set up of a T-cell donor registry. Front Immunol. https:// doi.org/10.3389/fimmu.2012.00410
104. Mackinnon S, Thomson K, Verfuerth S, Peggs K, Lowdell M (2008) Adoptive cellular therapy for cytomegalovirus infection following allogeneic stem cell transplantation using virus-specific $T$ cells. Blood Cells Mol Dis 40:63-67

105. Einsele H, Kapp M, Grigoleit GU (2008) CMV-specific cell therapy. Blood Cells Mol Dis 40:71-75

106. Clancy LE, Blyth E, Simms RM et al (2013) Cytomegalovirus-specific cytotoxic T lymphocytes can be efficiently expanded from granulocyte colony-stimulating factor-mobilized hemopoietic progenitor cell products ex vivo and safely transferred to stem cell transplantation recipients to facilitate immune reconstitution. Biol Blood Marrow Transplant 19:725-734

107. Samuel ER, Newton K, Mackinnon S, Lowdell MW (2012) Successful isolation and expansion of CMV-reactive T cells from G-CSF mobilized donors that retain a strong cytotoxic effector function. Brit J Haematol 160:87-100

108. Chalandon Y, Degermann S, Villard J et al (2006) Pretransplantation CMV-specific T cells protect recipients of T-cell-depleted grafts against CMVrelated complications. Blood 107:389-396

109. Blyth E, Clancy L, Simms R et al (2013) Donor-derived CMV-specific T cells reduce the requirement for CMV-directed pharmacotherapy after allogenic stem cell transplantation. Blood 121:3745-3758

110. Meyers JD, Flournoy N, Thomas ED (1986) Risk factors for cytomegalovirus infection after human marrow transplantation. J Infect Dis 153:478-488

111. Cervia JS, Wenz B, Ortolando GA (2007) Leukocyte reduction's role in the attenuation of infection risks among transfusion recipients. Clin Inf Dis 45:1008-1013

112. Hillyer CD, Lankford KV, Roback JD, Gillespie TW, Silberstein LE (1999) Transfusion of the HIV-seropositive patient: immunomodulation, viral reactivation and limiting exposure to EBV (HHV-4), CMV (HHV-5), and HHV-6, 7, and 8. Transfus Med Rev 13:1-17

113. Rubie H, Attal M, Campardou AM et al (1993) Risk factors for cytomegalovirus infection in BMT recipients transfused exclusively with seronegative blood products. Bone Marrow Transplant 11:209-214

114. Visconti MR, Pennington J, Garner SF, Allain JP, Willamson LM (2004) Assessment of removal of human cytomegalovirus from blood components by leukocyte depletion filters using real-time quantitative PCR. Transf Med 103:1137-1139

115. Lau W, Onizuka R, Krajden M (1998) Polymerase chain reaction based assessment of leukoreduction efficacy using a cytomegalovirus DNA transfected human T-cell line. J Clin Virol 38:109-116

116. Nichols GW, Price TH, Gooley T, Corey L, Boeckh M (2003) Transfusion-transmitted cytomegalovirus infection after receipt of leukoreduced blood products. Blood 101:4195-4200

117. Caspari G, Cassens U, Hebart H, Klüter $\mathrm{H}$, Mansouri-Taleghani B, Wüllenweber J (2003) Aktuelle Aspekte zur Vermeidung von transfusionsassoziierten CMV-Übertragungen. Stellungsnahme der Sektionen „Sicherheit in der Hämotherapie" und "Transplantation und Zelltherapie" der DGTI. Transfus Med Hemoth 20:195-198

118. Ronghe MD, Foot ABM, Cornish JM et al (2002) The impact of transfusion of leucodepleted platelet concentrates on cytomegalovirus disease 
after allogenic stem cell transplantation. $\mathrm{Br}$ J Haematol 118:1124-1127

119. Vamvakas EC (2005) Is white blood cell reduction equivalent to antibody screening in preventing transmission of cytomegalovirus by transfusion ? A review of the literature and meta-analysis. Transf Med Rev 19:181-199

120. Mainou M, Alahdab F, Tobian AAR et al (2016) Reducing the risk of transfusion-transmitted cytomegalovirus infection: a systematic review and meta-analysis. Transfusion. https:// doi.org/10.1111/trf.13478

121. Seed CR, Wong J, Polizzotto MN, Faddy H, Keller AJ, Pink J (2015) The residual risk of transfusiontransmitted cytomegalovirus infection associated with leucodepleted blood components. Vox Sang 109:11-17

122. Hall S, Danby R, Osman H et al (2015) Transfusion in CMV seronegative T-depleted allogenic stem cell transplant recipients with CMV-unselected blood components results in zero CMV transmissions in the era of universal leukocyte reduction: a UK dual centre experience. Transf Med 25:418-423

123. Preiksaitis JK, Brown L, McKenzie M (1988) The risk of cytomegalovirus infection in seronegative transfusion recipients not receiving exogenous immunosuppression. J Infect Dis 157:523-529

124. Roback JD (2002) CMV and blood transfusions. Rev Med Virol 12:211-219

125. Adler SP (1988) Data that suggest that FFP does not transmit CMV. Transfusion 28:604

126. Weber B, Rabenau $H$, Berger A et al (1995) Seroprevalence of HCV, HAV, HBV, HDV, CMV and HIV in high risk groups/Frankfurt a. M., Germany. Zentralbl Bakteriol 282:102-112

127. Sivakumaran M, Hutchinson RM, Wood JK, Revill JA, Ghosh K, Myint S (1993) Removal of cytomegalovirus (CMV) infected leucocytes from CMV seropositive blood units by bedside blood filtration. Br J Haematol 85:232-234

128. Larsson S, Soderberg-Naucler C, Wang FZ, Moeller E (1998) Cytomegalovirus DNA can be detected in peripheral blood mononuclear cells from all seropositive and most seronegative healthy blood donors over time. Transfusion 38:271-278

129. Asadullah K, Proesch S, Audring $\mathrm{H}$ et al (1999) A high prevalence of cytomegalovirus antigenaemia in patients with moderate to severe chronic plaque psoriasis: An association with systemic tumour necrosis factor alpha overexpression. Br J Dermatol 141:94-102

130. Drew WL, Tegtmeier G, Alter HJ, Laycock ME, Miner RC, Busch MP (2003) Frequency and duration of plasma CMV virema in seroconverting blood donors and recipients. Transfusion 43:309-313

131. Roback JD, Drew WL, Laycock ME, Todd D, Hillyer CD, Bush MP (2003) CMV DNA is rarely detected in healthy blood donors using validated PCR assays. Transfusion 43:314-321

132. Zanghellini F, Boppana SB, Emery VC, Griffiths PD, Pass RF (1999) Asymptomatic primary cytomegalovirus infection: Virologic and immunologic features. J Inf Dis 180:702-707

133. Zhang C, Buchanan H, Andrews W, Evans A, Pass RF (2006) Detection of cytomegalovirus infection during a vaccine clinical trial in healthy young women: seroconversion and virus shedding. J Clin Virol 35:338-342

134. Badami KG, McQuilkan-Bickerstaffe S, Wells JE, Parata M (2009) Cytomegalovirus seropreva- lence and 'cytomegalovirus-safe" seropositive blood donors. Epidemiol Infect 137:1776-1780

135. Ziemann M, Hennig H (2014) Prevention of transfusion-transmitted cytomegalovirus infections: Which is the optimal strategy? Transfus Med Hemoth 41:40-44

136. Hirsch HH, Lautenschlager I, Pinsky BA et al (2013) An international multicenter performance analysis of cytomegalovirus load tests. Clin Inf Dis 56:367-373

137. Pritt BS, Germer JJ, Gomez-Urena E et al (2013) Conversion to the COBAS AmpliPrep/COBAS TaqMan CMV test for management of CMV disease in transplant recipients. Diagn Microbol Inf Dis 75:440-442

138. Schnepf N, Scieux C, Resche-Riggon M et al (2013) Fully automated quantification of cytomegalovirus (CMV) in whole blood with the new sensitive Abbott realtime CMV assay in the era of the CMV international standard. J Clin Microbiol 51:2096-2102

139. Miller WJ, McCullough J, Balfour HH Jr et al (1991) Prevention of cytomegalovirus infection following bone marrow transplantation: A randomized trial of blood product screening. Bone Marrow Transplant 7:227-234

140. Bowden RA, Slichter SJ, Sayers M et al (1995) A comparison of filtered leukocyte-reduced and cytomegalovirus (CMV) seronegative blood products for the prevention of transfusion-associated CMV infection after marrow transplant. Blood 86:3598-3603

141. Narvios AB, Przepiorka D, Tarrant J, Chan KW, Champlin R, Lichtiger B (1998) Transfusion support using filtered unscreened blood products for cytomegalovirus-negative allogenic marrow transplant recipients. Bone Marrow Transpl 22:575-577

142. Gilbert GL, Hudson IL, Hayes K, James J (1989) Prevention of transfusion-acquired cytomegalovirus infection in infants by blood filtration to remove leukocytes. Lancet 339:1228-1231

143. Dumont LJ, Luka J, Van den Broeke T, Whitley P, Ambruso DR, Elfath MD (2001) The effect of leukocyte-reduction method on the amount of human cytomegalovirus in blood products: a comparison of apheresis and filtration methods. Blood 97:3640-3647

144. Ljungman P, Larsson $K$, Kumlien G et al (2002) Leukocyte depleted unscreened blood products give al low risk for CMV infection and disease in CMV seronegative allogenic stem cell transplant recipients with seronegative stem cell donors. Scand J Infect Dis 34:347-350

145. Narvios AB, de Lima M, Shah H, Lichtiger $B$ (2005) Transfusion of leucoreduced cellular blood components from cytomegalovirusunscreened donors in allogenic hematopoietic transplant recipients: analysis of 72 recipients. Bone Marrow Transpl 36:499-501

146. Laupacis A, Brown J, Costello B et al (2001) Prevention of posttransfusion CMV in the era of universal WBC reduction: A consensus statement. Transfusion 41:560-569

147. Roback JD, Bray RA, Hillyer CD (2000) Longitudinal monitoring of WBC subsets in packed RBC units after filtration: Implications for transfusion transmission of infections. Transfusion 40:500-506

148. Jayarama V, Marcello J, Olhagen A et al (2006) Development of models and detection methods for different forms of cytomegalovirus for the evaluation of viral inactivation agents. Transfusion $46: 1580-1588$

149. Jordan CT, Saakadze N, Newman JL et al (2004) Photochemical treatment of platelet concentrates with amotosalen hydrochloride and ultraviolet $\mathrm{A}$ light inactivates free and latent cytomegalovirus in a murine transfusion model. Transfusion 44:1159-1165

150. Prowse CV (2013) Component pathogen inactivation: a critical review. Vox Sang 104:183-199

151. Lin L, Hanson CV, Alter HJ et al (2005) Inactivation of viruses in platelet concentrates by photochemical treatment with amotosalen and long-wavelength ultraviolet light. Transfusion 45:580-590

152. Wagner SJ (2011) Developing pathogen reduction technologies for RBC suspensions. Vox Sang 100:112-121

153. Winter KM, Johnson L, Kwok M et al (2014) Red blood cell in vitro quality and function is maintained after S-303 pathogen inactivation treatment. Transfusion 54:1798-1807

154. Kaiser-Guignard J, Canellini G, Lion N, Abonnenc M, Osselaer JC, Tissot JD (2014) The clinical and biological impact of new pathogen inactivation technologies on platelet concentrates. Blood Rev 28:235-241

155. Schlenke P (2014) Pathogen inactivation technologies for cellular blood components: an update. Transfus Med Hemother 41:309-325

156. Keil SD, Bengrine A, Bowen R et al (2015) Inactivation of viruses in platelet and plasma products using a riboflavin-and-UV-based photochemical treatment. Transfusion 55:1736-1744

157. Kwon SY, Kim IS, Bae JE et al (2014) Pathogen inactivation efficacy of Mirasol PRT System and Intercept Blood System for non-leucoreduced platelet-rich plasma-derived platelets suspended in plasma. Vox Sang 107:254-260

158. Salunkhe V, van der Meer PF, de Korte D, Seghatchian J, Gutiérrez L (2015) Development of blood transfusion product pathogen reduction treatments: A review of methods, current applications and demands. Transfus Apher Sci 52:19-34

159. Prudent M, D'Alessandro A, Cazenave JP et al (2014) Proteome changes in platelets afte pathogen inactivation -an interlaboratory consensus. Transfus Med Rev 28:72-83

160. Butler C, Doree C, Estcourt LJ et al (2013) Pathogen-reduced platelets for the prevention of bleeding. Cochrane Database Syst Rev 28(3):CD9072

161. CPMP/BWP/268/95: Note for guidance on virus validation studies: design, contribution and interpretation of studies validating the inactivation and removal of viruses. http://www. ema.europa.eu/docs/en_GB/document_library/ Scientific_guideline/2009/09/WC500003684.pdf Zugegriffen: 31. Juli 2017

162. EMA/CHMP/BWP/706271/2010: Guideline on plasma derived medicinal products. http://www. ema.europa.eu/docs/en_GB/document_library/ Scientific guideline/2011/07/WC500109627.pdf Zugegriffen: 31. Juli 2017 